\title{
Frequency Modulation System and Bone Conduction Hearing Aid: Electroacoustic Verification
}

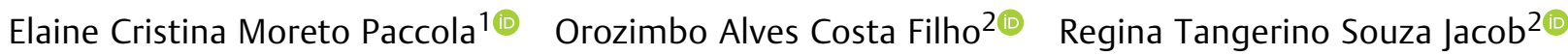 \\ ${ }^{1}$ Division of Hearing Health, Hospital de Reabilitação de Anomalias \\ Craniofaciais, Universidade de São Paulo, Bauru, SP, Brazil \\ Address for correspondence Regina Tangerino de Souza Jacob, PhD, \\ 2 Department of Speech Therapy, Faculdade de Odontologia de Bauru, \\ Al. Octavio Pinheiro Brisola, 9-75, Vila Universitária, Bauru (SP), \\ Universidade de São Paulo, Bauru, SP, Brazil
}

Int Arch Otorhinolaryngol 2021;25(4):e483-e489.

\begin{abstract}
Introduction A protocol has not yet been developed to perform electroacoustic measurements and behavioral tests to fit the frequency modulation (FM) system in bone conduction hearing aid (BCHA) users. Electroacoustic verification, with "FM transparency" achieved, ensures user audibility of FM transmitter and hearing aid signals.

Objective To propose and validate a protocol for electroacoustic verification of the FM system coupled to the BCHA.

Method Twenty-four sets of FM system and BCHA were submitted to electroacoustic verification, using a receiver and a plastic adapter to connect the BCHA to a $2 \mathrm{cc}$ coupler in the hearing instrument analyzer. The measurements were performed in the acoustic box, at $65 \mathrm{~dB}$ sound pressure level (SPL), with International Speech Test Signal (ISTS), first to the BCHA microphone and then to the FM system microphone, to determine the transparency, in which equivalent inputs for both microphones result in equivalent outputs. The FM gain or volume has been adjusted to try to gain transparency for the outputs of the two input devices.

Keywords Results Transparency was achieved for all sets evaluated, but in some combinations,

- microtia adjustments to the FM receiver gain over the manufacturer's default setting were required.

- hearing aids

Conclusion The proposed protocol proved to be effective for the electroacoustic

- hearing loss verification of the FM system coupled to the BCHA.
\end{abstract}

\section{Introduction}

Congenital ear malformations cause hearing difficulties, interfering with the development of speech and language skills and, consequently, impairing the social, emotional, cognitive, and academic development of the child. ${ }^{1}$

received

December 13, 2019

accepted

June 2, 2020

published online

September 24, 2020
DOI https://doi.org/ 10.1055/s-0040-1714128. ISSN 1809-9777.
The aim of amplification is to provide the child with hearing loss the opportunity to have access to the hearing environment and especially the speech. In children with permanent conductive hearing loss, when anatomically possible (anatomy of the external ear and external auditory (c) 2020. Fundação Otorrinolaringologia. All rights reserved.

This is an open access article published by Thieme under the terms of the Creative Commons Attribution-NonDerivative-NonCommercial-License, permitting copying and reproduction so long as the original work is given appropriate credit. Contents may not be used for commercial purposes, or adapted, remixed, transformed or built upon. (https://creativecommons.org/ licenses/by-nc-nd/4.0/)

Thieme Revinter Publicações Ltda., Rua do Matoso 170, Rio de Janeiro, RJ, CEP 20270-135, Brazil 
canal sufficient to retain the earmold and the hearing aid), the fitting of individual hearing aids by air conduction should be prioritized. When the anatomy is insufficient (significant anatomical malformations, chronically draining ears, etc.), the most appropriate option is bone conduction hearing aid (BCHA) fitting. ${ }^{2}$

A BCHA is an external device consisting of a microphone and an amplifier, a wire, and a vibrator, mounted on a metal or an elastic band, which will provide the pressure necessary to transmit the amplified acoustic signal (vibration) to the skull. ${ }^{2}$

A previous study ${ }^{3}$ demonstrated the benefit of BCHAs for acoustic signal perception and speech recognition in noise in individuals with congenital ear malformations. The study participants were also satisfied with the devices, despite the numerous disadvantages cited in the literature, such as headaches caused by metal band pressure on the mastoid, skin irritation from vibrator and metal band contact, poor sound quality, dissatisfaction with the aesthetic visibility of the components, as well as the negative psychosocial impact by the use of the apparatus.

Bone conduction amplification can also be provided by an osteo-anchored device called an osteo-anchored hearing aid or a bone-anchored hearing aid whose vibrator is attached to a surgically implanted support. This device causes less discomfort than traditional BCHAs because it eliminates metal headband pressure, reduces acoustic feedback and distortion, and improves hearing at higher frequencies since bone conduction occurs more directly. ${ }^{4}$ In Brazil, the Ministry of Health ${ }^{5}$ approved the use of osteo-anchored hearing aids for children older than five years; in younger children, the bone conduction amplification can be accomplished by means of an elastic band (Softband). 1,2,5

However, not all individuals with congenital ear malformations are candidates for surgery, and not all centers specializing in the rehabilitation of hearing impaired individuals have this feature.

Thus, BCHAs should be considered as an option when selecting and indicating the electronic sound amplification device for this population.

Children have higher hearing demands than adults to understand speech, particularly when listening is difficult (reduced speech signal intensity, noisy and/or reverberant environment). Improved audibility is required to provide better speech understanding, whether through increased speech signal strength, increased signal-to-noise ratio, or improvements in the listening environment. Thus, in the classroom, strategies or devices to address the effects of distance and reverberation should be included to optimize the use of hearing aids. ${ }^{2}$

Any child with a hearing impairment is a candidate for hearing assistance resources, which may include preferred classroom seating or a frequency modulation (FM) system, in which the teacher uses a microphone/transmitter and the child a receiver, coupled with his hearing aid. ${ }^{1}$

The purpose of fitting the FM system is to enable access to speech information when noise, distance, and reverberation interfere with speech signal pickup. This access is guaranteed by the improved signal-to-noise ratio that the FM system provides. The signal captured by the transmitter microphone is sent to the receiver, connected to the hearing aid with a gain advantage in the captured signal. ${ }^{6}$ The recommendation is that the FM system can provide a $10 \mathrm{~dB}$ advantage between the FM signal when compared with the signal captured by the hearing aid microphone., ${ }^{7,8}$

The FM signal perceived by the user is dependent on the amplification characteristics previously programmed in the hearing aid. In the ideal listening situation, when an FM system is connected to the amplifier device, the output response characteristics of the device should be maintained. This means that when connecting a receiver to the hearing aid, no modification in the amplification output response should be made or perceived by the user. ${ }^{7}$

The evaluation of the benefits of fitting an assistive technology, such as the FM system, in hearing aids or cochlear implants (CIs), should be composed of subjective and objective procedures. $^{6}$ As subjective assessment methods, there are speech in noise tests and questionnaires. In the objective evaluation, the electroacoustic verification, obtaining the "FM transparency" allows to assure audibility of both the FM transmitter signal and the air-conduction hearing aid signal consistently for the user and to make sure that the amplification offered by the hearing aid does not change when entering the FM system signal. ${ }^{7,9}$

"Transparency is achieved when the $65 \mathrm{~dB}$ SPL input to the FM microphone produces a result equal to the $65 \mathrm{~dB}$ SPL input to the microphone of the individual sound amplifier". 7,8

However, a protocol for the electroacoustic verification of the BCHA coupled FM system has not yet been developed. Thus, the objective of this study was to propose and validate a protocol for electroacoustic verification of the FM system, coupled to BCHAs.

\section{Method}

This is a descriptive cross-sectional study, developed in a hearing health service of the Brazilian Unified Health System. Electroacoustic Verification Protocol:

The electroacoustic verification protocol used in the present study was developed based on the recommendations of the American Academy of Audiology. ${ }^{7}$ It was necessary to use a plastic adapter and a 3-input receiver to couple the BCHA to the HA-1 coupler of the Verifit/Audioscan, Verifit (Division of Etymonic Design Incorporated, Ludwig St. Dorchester, ON, $\mathrm{CA}$ ), and the protocol was applied as described below and as shown in -Fig. $\mathbf{1}$ :

1. Calibrate the equipment Audioscan, Verifit (Division of Etymonic Design Incorporated, Ludwig St. Dorchester, ON, CA) with the HA-1 coupler;

2. Disconnect the wire that connects the hearing aid to the bone vibrator;

3,4 . Connect the wire (hearing aid) to the HA-1 coupler inside the test box, using a receiver and a plastic adapter;

5. Turn on the FM transmitter, checking its synchronization with the FM receiver; 

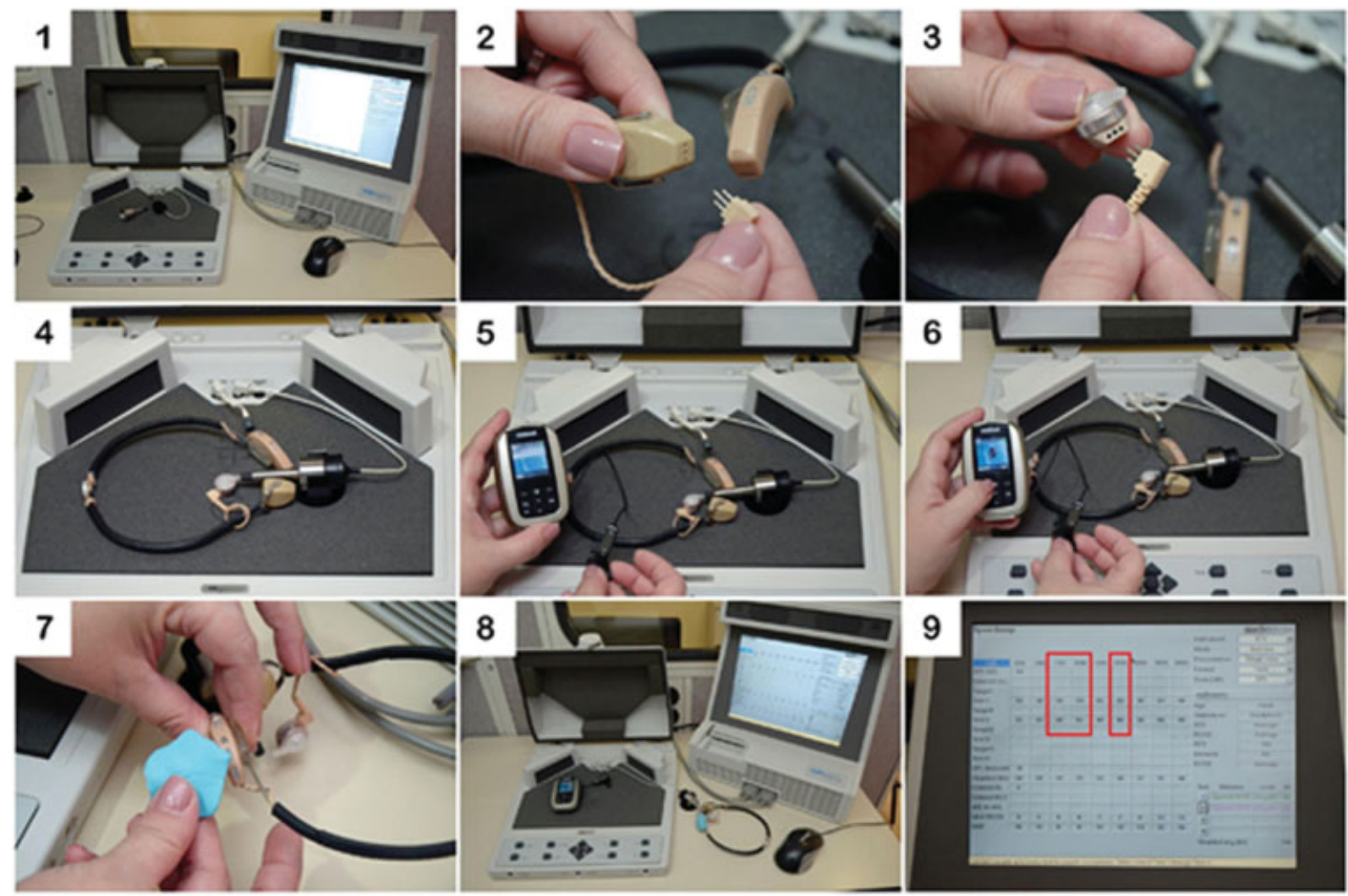

Fig. 1 Step-by-step for the electroacoustic verification-bone conduction hearing aid and FM system.

6. Set the microphone of the transmitter to the "mute" function; if this option is not available, seal it with dough; Draw curve 1 for a $65 \mathrm{~dB}$ SPL input (stimulus: International Speech Test Signal [ISTS]);

7. Seal the hearing aid's microphone;

8. Remove the BCHA (+ receiver + plastic adapter) still connected to the HA-1 coupler and the test microphone out of the test box and turn on the microphone of the FM transmitter and place it in the test box; Draw curve 2 under the same conditions as curve 1 ;

9. After performing both measurements, the results in $\mathrm{dB}$ SPL should be noted, and the average of the output differences calculated at the 3 frequencies of interest (750, 1,000, and 2,000 Hz).

Transparency is achieved when the average of the hearing aid + FM condition is equal to or less than $3 \mathrm{~dB}$ of the average of the hearing aid-only condition. When the difference is greater than $3 \mathrm{~dB}$, the receiver gain should be adjusted and measurements repeated.

\section{Procedures}

Three models of BCHAs: Phonak, Naída IUP, Naída ISP and Naída S ISP (Sonova, Stäfa, $\mathrm{CH}$ ) with headband, wire, and bone vibrator are programmed, with the prescriptive rule DSL v5.0 ${ }^{2}$ being adopted to ensure that the signal processing of the hearing aid has been adjusted to provide audibility and output response that are appropriate to the user's needs for different input signal levels, as well as to receive FM signal (FM $+M$ initial program option, automatic). ${ }^{7}$

Three FM transmitter models: Oticon, T31 Amigo, (Oticon, Smorum, DK), Phonak, SmartLink and Inspiro Premium (Sonova, Stäfa, $\mathrm{CH}$ ), three FM receiver models: Oticon, R2 (Oticon, Smorum, DK), Phonak, ML10i and ML11i (Sonova, Stäfa, $\mathrm{CH}$ ), and two shoe models: Phonak, AS10 and AS11 (Sonova, Stäfa, $\mathrm{CH}$ ), which were combined, according to - Table 1, totaling 24 sets of BCHAs and FM systems were submitted to the electroacoustic verification protocol.

In all 24 sets evaluated, it was possible to fit the FM receiver via direct audio input of BCHAs; In 13 sets (Phonak, FM Systems - Sonova, Stäfa, $\mathrm{CH}$ ), it was possible to fit the specific receiver and in 11 sets (Oticon FM Systems - Oticon, Smorum, DK) it was necessary to use a shoe and the universal receiver. The FM systems were initially programmed according to the standards established by the manufacturers, adopting the $0 \mathrm{~dB}$ gain for Phonak devices ${ }^{10}$ and $+8 \mathrm{~dB}$ for Oticon. ${ }^{11}$

For the various measurements, BCHAs and FM systems were placed inside a sound attenuation box consisting of a foamlined plastic box. To ensure repeatability of the electroacoustic verification protocol, each measurement was performed at least twice. The FM receiver gain was adjusted to try to achieve transparency for the outputs of both input devices. The Amigo T31 receivers of the Oticon brand have a gain adjustment range of $30 \mathrm{~dB}$. The default position is $+8 \mathrm{~dB}$. This means that the receiver gain can be increased by $22 \mathrm{~dB}$ and decreased by $8 \mathrm{~dB} .^{11}$ 
Table 1 Bone conduction hearing aids and frequency modulated systems (transmitters, receivers, and audio input shoes) submitted to the electroacoustic verification protocol

\begin{tabular}{|l|l|l|l|l|}
\hline $\mathbf{N}=\mathbf{2 4}$ & Bone conduction hearing aids & Transmitters & Receivers & Audio input shoes \\
\hline 2 & Naída I UP (Phonak) & SmartLink (Phonak) & ML 10i (Phonak) & - \\
\hline 3 & Naída I SP (Phonak) & SmartLink (Phonak) & ML 11i (Phonak) & - \\
\hline 1 & Naída I UP (Phonak) & Inspiro P (Phonak) & ML10i (Phonak) & - \\
\hline 3 & Naída I SP (Phonak) & Inspiro P (Phonak) & ML 11i (Phonak) & - \\
\hline 4 & Naída S ISP (Phonak) & Inspiro P (Phonak) & ML 11i (Phonak) & - \\
\hline 4 & Naída I UP (Phonak) & T31 (Oticon) & R2 (Oticon) & AS10 (Phonak) \\
\hline 2 & Naída I SP (Phonak) & T31 (Oticon) & R2 (Oticon) & AS11 (Phonak) \\
\hline 5 & Naída S IS (Phonak) & T31 (Oticon) & R2 (Oticon) & AS11 (Phonak) \\
\hline
\end{tabular}

All electroacoustic measurements were performed with Audioscan, Verifit equipment (VF-1) and HA-1 coupler, with the speech stimulus ISTS at $65 \mathrm{~dB}$ SPL.

Statistical analysis was performed for all models and brands of BCHAs, FM transmitters, and receivers used in this study. The comparison of the transparency results between different brands and models was performed by the analysis of variance (ANOVA) method, and the comparison from the transparency results between BCHA-only and BCHA plus FM was performed using the paired $t$-test.

\section{Results}

Transparency was achieved for all combinations (100\%) of BCHAs and FM systems of this study, as shown in - Table 2. Some combinations of BCHAs and FM systems from different manufacturers $\left({ }^{*}\right)$ required gain adjustments of the FM receiver (reduction) over the manufacturer's default setting. To adjust the gain of the R2/Oticon receiver, the T31 Amigo/ Oticon transmitter was used, and the adjustment ranged from +8 to $0 \mathrm{~dB}$, and, after such adjustment, the transparency was reached.

There was no significant difference in the comparison of transparency results between models of BCHAs $(p=0.780)$, as shown in - Fig. 2.

There was also no statistical difference in the comparison of transparency results between FM system models $(p=0.764)$, according to - Fig. 3 .

\section{Discussion}

The ability to fit the FM receiver via direct audio input to the hearing aids results in a listening condition for the patient that combines the operation of two microphones, one local (from the hearing aid) and one remote (from the FM transmitter). This combination allows the patient to perceive ambient sounds and monitor their own voice while consistently listening to the main speaker's voice picked up by the FM transmitter microphone. ${ }^{7}$

Considering this, the objective of the electroacoustic verification of the FM system is to ensure that, from an electroacoustic point of view, both the signal perceived by the hearing aid microphone and the signal provided by the FM system provide audibility for the entire spectrum of speech sounds without distortion. 8,12

In the present study, despite the adaptations and the need for adjustments in receiver gain and repetition of measurements, it was observed that electroacoustic verification is a simple, fast, and effective process, as mentioned in the guidelines available in the literature, to perform these measurements. ${ }^{7,9}$ In devices in which a specific FM receiver was used, that is, a receiver from the same manufacturer of the BCHA, there was no need to adjust the gain. In $45 \%$ of the devices that required the use of a shoe and the universal FM receiver, that is, the receiver is made by a different manufacturer than the one of the BCHA, it was necessary to adjust the gain of the device.

In their study, ${ }^{13}$ in the electroacoustic evaluation of the FM system coupled to the Nucleus 5 speech processor, the authors achieved transparency in the 7 (100\%) cases evaluated with $+2 \mathrm{~dB}$ FM gain, without the need for further adjustment since all FM receivers coupled to the Nucleus 5 speech processor were specific (ML14i).

In another study ${ }^{14}$ that combined 4 transmitters and 4 receivers for transparency assessment with the Nucleus 5 speech processor, the gain settings required to achieve transparency were highly variable. The authors justified the need for gain adjustment by the fact that they used a universal receiver (MLxi), which requires an adapter (shoe) for connection to the $\mathrm{CI}$.

Other researchers, ${ }^{13,14}$ when performing electroacoustic measurements on CI-coupled FM systems, achieved transparency for most combinations of $\mathrm{CI}$ and FM, but adjustments in FM gain or volume relative to the manufacturer's default setting were necessary.

Objective verification measures are part of the hearing aid fitting protocols, both for the pediatric population ${ }^{2}$ and for adult and elderly patients. In children, the commitment to ensure quality of audibility is even greater, regardless of their stage of development. When children get to school age, the ability to hear and understand verbal information is critical to classroom learning. ${ }^{12}$ Thus, Thibodeau and Wallace ${ }^{15}$ emphasize the importance of performing electroacoustic verification of assistive 
Frequency Modulation System and Bone Conduction Hearing Aid Paccola et al. 487

Table 2 Transparency results-difference between bone conduction hearing aids and frequency modulation systems

\begin{tabular}{|c|c|c|c|c|c|c|}
\hline \multirow[t]{2}{*}{$N=24$} & \multirow[t]{2}{*}{$\mathrm{BCHA} / \mathrm{BCHA}+\mathrm{FM}$} & \multicolumn{4}{|c|}{ TRANSPARENCY } & \multirow[t]{2}{*}{ Difference $\mathrm{BCHA} / \mathrm{BCHA}+\mathrm{FM}$} \\
\hline & & 750 & 1,000 & 2,000 & Mean & \\
\hline \multirow[t]{2}{*}{1} & Naída I UP & 101 & 96 & 90 & 95.66 & \multirow[t]{2}{*}{1.67} \\
\hline & Smartlink + ML 10i & 102 & 98 & 92 & 97.33 & \\
\hline \multirow[t]{2}{*}{2} & Naída I UP & 76 & 72 & 76 & 74.66 & \multirow[t]{2}{*}{2.67} \\
\hline & Smartlink + ML 10i & 80 & 75 & 77 & 77.33 & \\
\hline \multirow[t]{2}{*}{3} & Naída I SP & 72 & 65 & 63 & 66.66 & \multirow[t]{2}{*}{3} \\
\hline & Smartlink + ML 11i & 75 & 69 & 65 & 69.66 & \\
\hline \multirow[t]{2}{*}{4} & Naída I SP & 83 & 78 & 77 & 79.33 & \multirow[t]{2}{*}{2} \\
\hline & Smartlink + ML 11i & 85 & 80 & 79 & 81.33 & \\
\hline \multirow[t]{2}{*}{5} & Naída I SP & 83 & 74 & 75 & 77.33 & \multirow[t]{2}{*}{2} \\
\hline & Smartlink + ML 11i & 85 & 77 & 76 & 79.33 & \\
\hline \multirow[t]{2}{*}{6} & Naída I UP & 77 & 74 & 71 & 74 & \multirow[t]{2}{*}{1.67} \\
\hline & Inspiro P + ML10i & 73 & 72 & 72 & 72.33 & \\
\hline \multirow[t]{2}{*}{7} & Naída I SP & 81 & 73 & 72 & 75.33 & \multirow[t]{2}{*}{1.67} \\
\hline & Inspiro $\mathrm{P}+\mathrm{ML} 11 \mathrm{i}$ & 79 & 73 & 69 & 73.66 & \\
\hline \multirow[t]{2}{*}{8} & Naída I SP & 79 & 75 & 76 & 76.66 & \multirow[t]{2}{*}{2} \\
\hline & Inspiro $\mathrm{P}+\mathrm{ML} 11 \mathrm{i}$ & 81 & 77 & 78 & 78.66 & \\
\hline \multirow[t]{2}{*}{9} & Naída I SP & 81 & 77 & 76 & 78 & \multirow[t]{2}{*}{2} \\
\hline & Inspiro P + ML 11i & 84 & 78 & 78 & 80 & \\
\hline \multirow[t]{2}{*}{10} & Naída S ISP & 88 & 85 & 84 & 85.66 & \multirow[t]{2}{*}{1.33} \\
\hline & Inspiro P+ML 11i & 87 & 86 & 86 & 86.33 & \\
\hline 11 & Naída S ISP & 78 & 75 & 74 & 75.66 & 2.34 \\
\hline & Inspiro $\mathrm{P}+\mathrm{ML} 11 \mathrm{i}$ & 81 & 78 & 75 & 78 & \\
\hline 12 & Naída S ISP & 78 & 71 & 70 & 73 & 2 \\
\hline & Inspiro $\mathrm{P}+\mathrm{ML} 11 \mathrm{i}$ & 79 & 73 & 73 & 75 & \\
\hline 13 & Naída S ISP & 86 & 84 & 82 & 84 & 0 \\
\hline & Inspiro P + ML 11i & 85 & 85 & 82 & 84 & \\
\hline 14 & Naída I UP & 81 & 75 & 73 & 76.33 & 0 \\
\hline & $\mathrm{T} 31+\mathrm{R} 2+\mathrm{AS} 10$ & 81 & 74 & 74 & 76.33 & \\
\hline $15^{*}$ & Naída I UP & 80 & 75 & 77 & 77.33 & 3 \\
\hline & $\mathrm{T} 31+\mathrm{R} 2+\mathrm{AS} 10$ & 83 & 78 & 80 & 80.33 & \\
\hline $16^{*}$ & Naída I UP & 96 & 86 & 75 & 85.66 & 2 \\
\hline & $\mathrm{T} 31+\mathrm{R} 2+\mathrm{AS} 10$ & 99 & 88 & 76 & 87.66 & \\
\hline 17 & Naída I UP & 83 & 74 & 75 & 77.33 & 2 \\
\hline & $\mathrm{T} 31+\mathrm{R} 2+\mathrm{AS} 10$ & 85 & 77 & 76 & 79.33 & \\
\hline 18 & Naída I SP & 98 & 90 & 88 & 92 & 0.33 \\
\hline & $\mathrm{T} 31+\mathrm{R} 2+\mathrm{AS} 11$ & 98 & 90 & 89 & 92.33 & \\
\hline $19^{*}$ & Naída I SP & 89 & 83 & 77 & 83 & 2.33 \\
\hline & $\mathrm{T} 31+\mathrm{R} 2+\mathrm{AS} 11$ & 91 & 86 & 79 & 85.33 & \\
\hline 20 & Naída S ISP & 88 & 80 & 86 & 84.6 & 1 \\
\hline & $\mathrm{T} 31+\mathrm{R} 2+\mathrm{AS} 11$ & 90 & 82 & 85 & 85.6 & \\
\hline $21^{*}$ & Naída S ISP & 94 & 86 & 78 & 86 & 2.66 \\
\hline & $\mathrm{T} 31+\mathrm{R} 2+\mathrm{AS} 11$ & 95 & 88 & 83 & 88.66 & \\
\hline
\end{tabular}

(Continued) 
Table 2 (Continued)

\begin{tabular}{|l|l|l|l|l|l|l|}
\hline \multirow{2}{*}{$\mathbf{N}=\mathbf{2 4}$} & \multirow{2}{*}{ BCHA/BCHA+FM } & \multicolumn{4}{|c|}{ TRANSPARENCY } & \multirow{2}{*}{ Difference BCHA/BCHA+FM } \\
\cline { 3 - 6 } & & 750 & 1,000 & 2,000 & Mean & \multirow{2}{*}{2.67} \\
\hline \multirow{2}{*}{$22^{*}$} & Naída S ISP & 87 & 82 & 84 & 84.33 & \\
\cline { 2 - 6 } & T31+R2+ AS11 & 89 & 85 & 87 & 87 & 2 \\
\hline \multirow{2}{*}{23} & Naída S ISP & 83 & 80 & 72 & 78.33 & \multirow{2}{*}{0.66} \\
\cline { 2 - 6 } & T31+R2+ AS11 & 85 & 82 & 74 & 80.33 & \\
\hline
\end{tabular}

Abbreviations: FM, frequency modulation; $\mathrm{BCHA}$, bone conduction hearing aid.

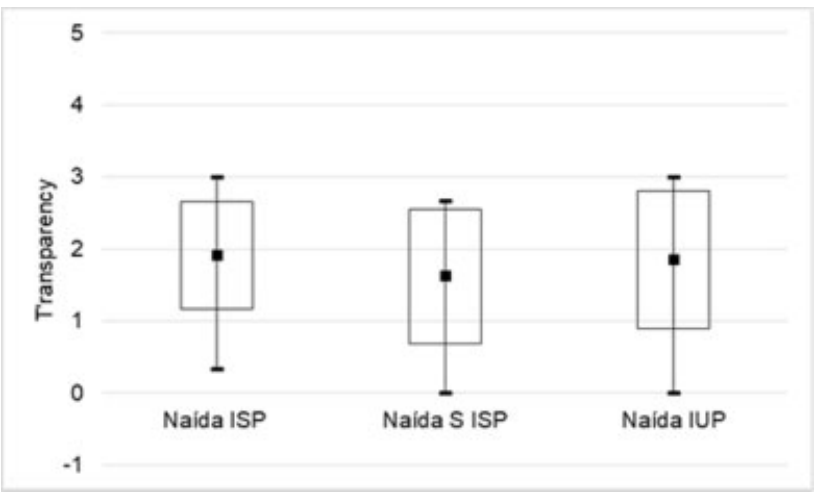

Fig. 2 Comparison of transparency results between bone conduction hearing aid models (analysis of variance).

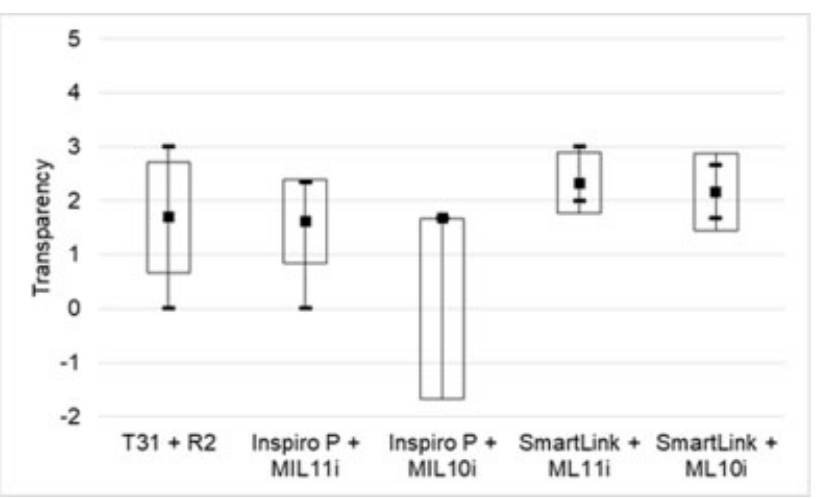

Fig. 3 Comparison of transparency results between FM system models (Variance Analysis).

technology devices, such as the FM system, to ensure that they fulfill their purpose of favoring the signal-to-noise ratio.

In future studies, subjective evaluation (speech in noise tests and self-assessment questionnaires) may provide new information on the benefit and satisfaction of users of these devices.

\section{Conclusions}

The electroacoustic verification protocol proposed in this study proved to be effective and allowed the electroacoustic verification of the FM system coupled to the BCHA. The protocol may be used in new research and clinical practices, provided the need to adjust the gain/volume of the FM system is considered, especially when the evaluated set is composed of devices from different manufacturers. The behavioral measures suggested by the American Academy of Audiology ${ }^{7}$ should also be advocated to ensure proper adjustment of the FM system to BCHAs.

\section{Conflict of Interests}

The authors declare that there is no conflict of interests.

\section{References}

1 Kesser BW, Meyeres AD. Aural Atresia. May 23, 2018. Available at: https://emedicine.medscape.com/article/878218-overview\#a11. Accessed June 06, 2018.

2 American Academy of Audiology. Clinical Practice Guidelines Pediatric Amplification June, 2013. Available at: http://galster.net/ wp-content/uploads/2013/07/AAA-2013-Pediatric-Amp-Guidelines. pdfa. Accessed June 01, 2018.

3 Paccola ECM, Fernandes JC, Mondelli MFCG. Amplification by bone conduction in congenital malformations: patient benefits and satisfaction. Rev Bras Otorrinolaringol (Engl Ed) 2013;79(03): 359-365https://www.ncbi.nlm.nih.gov/pubmed/23743753

4 Jardim IS, Brito RV, Costa OA. Próteses auditivas cirurgicamente implantáveis de orelha média. In: Boéchat EM, Menezes PM, Couto CM, Frizzo ACF, Scharlach RC, Anastasio ART. Tratado de Audiologia. Rio de Janeiro, RJ: Editora Guanabara-Koogan; 2015: 343-52

5 Brasil. Portaria $n^{\circ} 2.776$, de 18 de dezembro de 2014. Aprova diretrizes gerais, amplia e incorpora procedimentos para a Atenção Especializada às Pessoas com Deficiência Auditiva no Sistema Único de Saúde (SUS). December 18, 2014. Available at: http://bvsms. saude.gov.br/bvs/saudelegis/gm/2014/prt2776_18_12_2014.html. Accessed June 01, 2018.

6 Jacob RTS, Queiroz-Zattonni M. Sistema de Frequência Modulada. In: Boéchat EM, Menezes PM, Couto CM, Frizzo ACF, Scharlach RC, Anastasio ART. Tratado de Audiologia. Rio de Janeiro, RJ: Editora Guanabara-Koogan; 2015:298-310

7 American Academy of Audiology - Remote Microphone Hearing Assistance Tecnologies for Children and Younth from Birth to 21 Years. April, 2011. Available at: https://www.audiology.org/ publications-resources/document-library/hearing-assistancetechnologies. Accessed June 02, 2018.

8 Smriga D. Clinical verification of ear level FM systems: classroom \& personal use applications. May 27, 2016. Available at: https:// www.audiologyonline.com/articles/clinical-verification-ear-level-fm-17322. Accessed June 02, 2018.

9 American Speech-Language-Hearing Association. Guidelines for Fitting and Monitoring FM Systems. 2002. Available at: https:// 
www.asha.org/policy/GL2002-00010.htm. Accessed June 02, 2018.

10 Phonak. Fitting Guide MLxi and MLxi Baha. April 15, 2010. Available at: https://www.phonakpro.com/content/dam/phonakpro/gc_hq/en/ products_solutions/wireless_accessories/roger_receivers/documents/ mlxi-and-mlxi-baha-fitting-guide.pdf. Accessed June 02, 2018.

11 Oticon. Amigo Quick Fitting Guide for Audiologists. Available at: https://www.oticon.com/-/media/oticon-us/main/download-center/amigo/pi/108605-amigo-quick-fitting-guide-for-audiologists. pdf. Accessed June 02, 2018.

12 Lewis D, Eiten L. FM Systems and Comunication Access for Children. In: Seewald R, Tharpe AM. Comprehensive Book of Pediatric Audiology. 2016:553-64
13 Fidêncio VLD, Jacob RTS, Tanamati LF, Bucuvic ÉC, Moret ALM. Electroacoustic verification of frequency modulation systems in cochlear implant users. Rev Bras Otorrinolaringol (Engl Ed) 2019;85(02): 162-169

14 Schafer EC, Musgrave E, Momin S, Sandrock C, Romine D. A proposed electroacoustic test protocol for personal FM receivers coupled to cochlear implant sound processors. J Am Acad Audiol 2013;24(10):941-954https://www.ncbi.nlm.nih.gov/pubmed/ 24384080

15 Thibodeau LM, Wallace S. Guidelines and standards for wireless technology for individuals with hearing loss. Semin Hear 2014; 35:159-167 Available at https://www.thieme-connect.com/ products/ejournals/abstract/10.1055/s-0034-1383501 